\title{
RAPD Marker Conversion into a SCAR Marker for Rapid Identification of Johnsongrass [Sorghum halepense (L.) Pers.]
}

\author{
Wenju ZHANG ${ }^{1}$, Liping YIN², Shasha WEI ${ }^{1}$, Zhirui DENG ${ }^{1}$, Jianping YI², Renqi WU ${ }^{1}$, Qin CHEN ${ }^{*}$ \\ ${ }^{1}$ Shanghai University, School of Life Science, Shanghai, Shanghai Key Laboratory of Bio-Energy \\ Crops, 200444,China; chenqincc@staff.shu.edu.cn ("corresponding author) \\ ${ }^{2}$ Shanghai Entry-Exit 2uarantine and Inspection Bureau, Shanghai, 200135, China
}

\begin{abstract}
Johnsongrass [Sorghum halepense (L.) Pers.] is a malignant weed in the world, threatening biodiversity at invaded habitats in more than 50 countries. Because of similarity in morphological characters, S. halepense and its relatives, S. almum, S. nitidum, S. propinquum, S. sudanense, and S. bicolor, etc. was difficult to identify. As a supplementary methodolgy for morphology identification, a molecular detection method was established. Sequence Characterized Amplified Regions (SCAR) marker is a recent established, reliabile, and stable molecular marker based on RAPD maker, an effective way for germplasm identification. In this study, one specific band of S.halepense was screened by 163 pairs of RAPD primers. According to the sequences of the band, a pair of special SCAR primers SH1/SH2 was designed and verified by 65 Sorghum DNA samples from all over the world. The results showed SCAR primers SH1/SH2 can be used to distinguish S.halepense and its relatives rapidly with three exceptions of Australia geotypes.
\end{abstract}

Keywords: breeding, convert, RAPD marker, SCAR marker, Sorghum halepense

\section{Introduction}

Sorghum halepense (L.) Pers. is perennial grass with the ribbed leaf sheath, conspicuous midrib, the large purplish panicles, and the extensively creeping rhiaomes (Holm et al., 1977). It originated from hybridization of Sorghum arundinaceum and Sorghum propinquum through chromosome doubling. Chromosome: $2 \mathrm{n}=4 \mathrm{x}=40$. Sorghum halepense, native to Mediterranean region, is one of the ten hardness weeds in the world that reduces in more than 30 crop species and various fruits and threatens biodiversity in invaded habitats in no less than 50 countries (Holm et al., 1977). The striking invasiveness and minacity of sorghum halepense are mainly on: 1) high reproductive capacity; 2) being an alternate host of various pathogen species, which intimidates the cultivations of local crops; 3 ) evident allelopathic effects and toxicity to livestock; 4) broad resistances to groups of herbicides; and 5) readiness of crossing with relative species naturally. And the potential hybrids in the one hand may gain even higher invasiveness. In the other hand, gene flow may cause crop species genepolluted (Jang et al., 2009).

Caryopsis is the principal mean of the spread of sorghum halepense. Huge numbers of caryopses are readily to distribute with wind, water, birds and other animals. More importantly, its seed dissemination frequently attains by hitchhiking on goods traded allover the world, in particular, by mixing in forage, crop seeds and raw grains, such as sorghum (Sorghum bicolor), soybean (Glycine max) and maize (Zae mays). Therefore, as the key content of its control, caryopsis detection and identification should be the core task in Sorghum halepense quarantine. However, Sorghum halepense bears similarity to its relative species and the seeds may be deformed and abrased during storage, loading and unloading. It is very difficult to distinguish them morphologically from each other (Yin et al., 2004).

Molecular biological methods, especially, molecular markers have obvious advantages for identifying Sorghum halepense from seeds of its relative species. Therefore, molecular markers take play an important role in both of genetic diversity and identification of sorghum species. Varieties of molecular markers such as RFLP (Guo et al., 2005), RAPD (Li et al., 2007), ISSR (Fang et al., 2008), etc. have been applied in sorghum germplasm identification and analysis of genetic diversity research.

The RAPD markers which were established by Williams et al. (1990) can give polymorphism information covering entire genome by a number of different primers. Because of its features - simple, rapid, efficient, and its short cycle, RAPD markers are widely used in genetic diversity and breeding of tea and other plant in recent years (Chen et al., 1999). However, the application of these RAPD markers has been restricted to the laboratories in which they were identified. The RAPD technique has been known for its reproducibility problems mainly among different laboratories (Kesseli et al., 1992; Penner et al., 1993). SCARs (Kesseli et al., 1992) have been proposed as an alternative procedure to increase the reproducibility 
of the RAPD technique. SCAR marker is a new molecular markers based on RAPD maker (Paran and Michelmore, 1993). For its reliable, stable, long-term using, SCAR marker molecular is a new effective way for identification of germplasm. A large number of SCAR markers have now used on soybean, wheat, corn, mulberry, tobacco and other plants on genetic breeding research, however, this technology had not yet been applied in Sorghum halepense. The objective of this study was to find the special segment with random primer in genomic DNA of Sorghum halepense, and then convert the RAPD maker to a SCAR marker in order to improve the stability of molecular identification of Sorghum halepense.

\section{Materials}

\section{Plant materials}

Sixty five Sorghum genus seeds were obtained from Yin Liping, Technical Center of Plant and Animal Quarantine, Shanghai Entry-Exit Inspection and Quarantine Bureau, and those specimens were collected from Australian Tropical Crops and Forages Collection - Queensland Department of Primary Industries and Fisheries, Institute of Botany - the Chinese Academy of Sciences, The Chinese Academy of Agricultural Sciences and Botanical Gardens over the world. To estimate the differences, thirteen species including $S$. halepense and its relatives $S$. almum, $S$. bicolor, $S$. hybrid, $S$. vulgare, $S$. saccharatum, $S$. nitidum, S. arumdinaceum, $S$. verticilliflorum, $S$. drummondii, $S$. sudanse, Silk sorghum, $S$. propinum were used (Tab. 1).

Tab. 1. Accessions list of samples used in the study

\section{Reagents and random primers}

The reagents were purchased from Shanghai Sangon Biological Engineering Technology \& Service Co. Ltd, TaKaRa Biotechnology (Dalian) Co. Ltd and Tiangen Biotech (Beijing) Co. Ltd. The random primers were synthesized by Shanghai Sangon Biological Engineering Technology \& Service Co. Ltd.

\section{Methods}

Extraction of Genomic DNA from seeds of S.halepense and its relative species

Total DNA was extracted from seed powder using the method improved by our laboratory (Chen et al., 2009). Based on the reported chloroplast gene matK-trnK sequences of S.bicolor, a pair of universal primers were designed, CP3: 5' GTGTTGACGAGATTTCTGTT 3', CP4 5' GGGTTGCTAACTCAATGGTA 3'. The universal primers were used to identify whether the DNA extracted from the seeds can be used as the template.

\section{RAPD-PCR amplification}

The DNA bulks were amplified by the RAPD technique (Williams et al., 1990) with 163 random decamer primers with more than three repeats. Each amplification reaction of $20 \mathrm{ul}$ contained $2 \mu \mathrm{L} 10 \times \mathrm{PCR}$ buffer (TIANGEN, China), $0.4 \mathrm{mM}$ Mix-dNTP (Tiangen, China), $0.25 \mathrm{mM}$ of primer, one unit of Taq DNA polymerase (Tiangen, China) and 25 ng of DNA. Each amplification cycle consisted of the following step: $30 \mathrm{~s}$ at $94^{\circ} \mathrm{C}, 40 \mathrm{~s}$

\begin{tabular}{|c|c|c|c|c|c|c|c|}
\hline Code & Origin & Code & Origin & Code & Origin & Code & Origin \\
\hline Shall & U.S.A.(Texan,) & Shal18 & U.S.A(Peiolia) & Sbic2 & Unknown & Snit4 & Australia \\
\hline Shal2 & U.S.A(Peiolia) & Shal19 & Australia & Sbic3 & Argentina & Sarul & Australia \\
\hline Shal3 & U.S.A & Shal20 & U.S.A & Sbic4 & Briazil & Sver1 & Unknown \\
\hline Shal 4 & U.S.A(Peiolia) & Salm1 & Argentina & Sbic 5 & France & Sdrul & Ethiopia \\
\hline Shals & U.S.A(Peiolia) & Salm2 & Argentina & Sbic6 & U.S.A & Sdru2 & Kenya \\
\hline Shal6 & U.S.A(Peiolia) & Salm3 & Argentina & Sbic7 & Unknown & Sdru3 & Portugal \\
\hline Shal7 & U.S.A & Salm4 & Argentina & Sbic8 & Unknown & Sdru4 & Zaire \\
\hline Shal8 & U.S.A(Peiolia) & Salm5 & Argentina & Sbic9 & China(Hebei) & Ssudl & China(Hunan) \\
\hline Shal9 & China(Nanjing) & Salm6 & Australia & Shybl & Unknown & Ssud2 & China(Nanjing) \\
\hline Shal10 & China(Nanjing) & Salm7 & Ethiopia & Svul1 & Unknown & Ssud3 & Argentina \\
\hline Shal11 & China(Nanjing) & Salm8 & Argentina & Ssacl & Unknown & Ssud4 & China(Hunan) \\
\hline Shal12 & China(Nanjing) & Salm9 & Argentina & Ssac2 & Unknown & Silk1 & Australia \\
\hline Shal13 & Argentina & Salm10 & Argentina & Ssac3 & China(CAAS) & Sprol & China(Guangxi) \\
\hline Shal14 & Australia & Salm11 & Australia & Ssac4 & Unknown & Spro2 & China(Fujian) \\
\hline Shal15 & China(Xiamen) & Salm12 & Australia & Snit1 & Australia & & \\
\hline Shall6 & U.S.A & Salm13 & Australia & Snit2 & China(Lianyungang) & & \\
\hline Shal17 & U.S.A(Peiolia) & Sbicl & Unknown & Snit3 & Australia & & \\
\hline
\end{tabular}

Shal1 Shal20: S.halepense; Salm1 Salm13: S.almum; Sbic1 Sbic9: S.bicolor; Shyb1: S.hybrid; Svull: S.vulgare; Ssac1 Ssac4: S.saccharatum; Snit1 Snit4: S.nitidum; Saru1: S.arundinaceum; Sver1: S.verticilliflorum; Sdru1 Sdru4: S.drummondii; Ssud1 Ssud4: S.sudanse; Silk1: Silk1: Silk Sorghum; Spro1 Spro2: S.propinum 
308

at $36^{\circ} \mathrm{C}$ and $80 \mathrm{~s}$ at $72^{\circ} \mathrm{C}$. After 40 cycles, samples were submitted to $6 \mathrm{~min}$ at $72^{\circ} \mathrm{C}$ and finally kept at $4^{\circ} \mathrm{C}$. Amplification products were separated on $1.5 \%$ agarose gels containing $10 \mathrm{mg} / \mathrm{ml}$ ethidium bromide, immersed in TAE. The DNA bands were visualized under UV light and photographed with the aid of the BIO-RAD Gel DOC2000. Three representative templates from sorghum genus were selected for screening, and then we selected several polymorphic primers from 163 pairs of RAPD primers, expanding the template to seven for further screening in order to select the target specific segment.

Cloning and sequencing the RAPD specific fragment of S.halepense

The RAPD marker band of S.halepense specific was cloned in vector pMD18-T. Competent DH5 $\alpha$ Escherichia coli cells were transformed and mini-prep DNA from white colonies was sequenced with M13 universal primers flanking the insert.

\section{Design and validation of SCAR primers}

The sequence data was used to design and synthesize two specific primers of $S$. halepense each containing 18-19 nucleotides including the sequence of the original RAPD primer listed in 1.2.2. The SCAR primers were verified by 65 sorghum DNA samples. The thermocycler was programmed for 35 cycles: $30 s$ at $94^{\circ} \mathrm{C}, 40 s$ at $55^{\circ} \mathrm{C}$, and 80 $s$ at $72^{\circ} \mathrm{C}$.

\section{The RAPD cluster analysis of several sorghum samples}

A total of 19 RAPD primers (S101, S117, S125, S127, S133, S134, S137, S147, S151, S164, S178, S187, S194, S201, S224, S226, S227, S248, S253) were selected to amplify one S. bicolor sample (Sbic9), four S.halepense samples (Shal7, Shal12, Shal15, Shal19) with different geographical origin and $12 \mathrm{~S}$. almum samples (Salm2Salm13). The cluster of the fingerprints was analysed by SPSS software.

\section{Results and analysis}

\section{Cloning and sequencing the RAPD specific fragment of} S. halepense

After screening with the three representative sorghum sample, 8 primers were selected from 163 primers. The RAPD-PCR electropherogram amplication of the three samples with eight different primers in primary screen was shown in Fig. 1. Adding another three $S$. halepense samples with different geographic origin and one $S$. almum sample which is the nearest relative species of $S$. halepense, a further screening was carried out from the 8 primers obtained in the first screening. The results showed that a specific band could be amplified by primer $S 151$ when the sample was S. halepense. The electropherogram was shown in Fig. 2. Sequenced by Sangon Co. Ltd. (Shanghai), the actual size of the fragment was 510bp, named JGL0924, shown in Fig. 3. Inputing the sequence to NCBI (national center biotechnology information) database for nucleotide BLAST analysis, results showed no high homological sequence in the existing sequences in GeneBank.

\section{SCAR-PCR amplification}

According to the sequence, one pair of $S$. halepense specific primers were designed based on the random primer S151. The sequences of the SCAR primers were shown in Tab. 2. The electropherogram of PCR amplification with CP3/CP4 in Fig. 4, 5, 6 showed positive results indicating that the genomic DNA of all sorghum genus samples was available in this study. The verification results of the specific primers $\mathrm{SH} 1 / \mathrm{SH} 2$ were shown in Tab. 3. The amplification results of $20 \mathrm{~S}$. halepense samples had the specific bands. Except three Australia $S$. almum, the amplification results of other $10 \mathrm{~S}$. almum samples, $9 \mathrm{~S}$. bicolor samples, $1 S$. hybrid sample, $1 S$. vulgare sample, $4 S$. saccharatum samples, $4 S$. nitidum samples, $1 S$. arundinaceum sample, $1 S$. verticilliflorum sample, $4 S$. drummondii samples, $4 S$. sudanse, 1 Silk Sorghum and $2 S$. propinum samples were
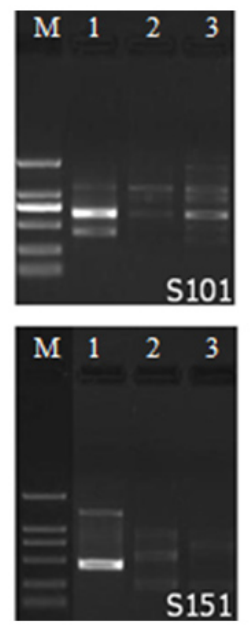
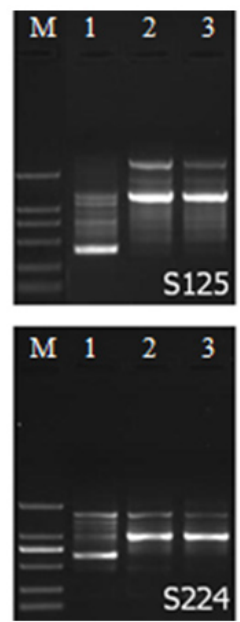
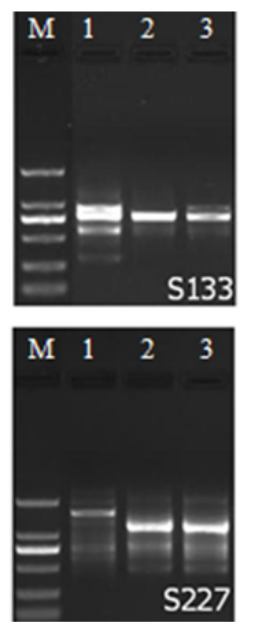
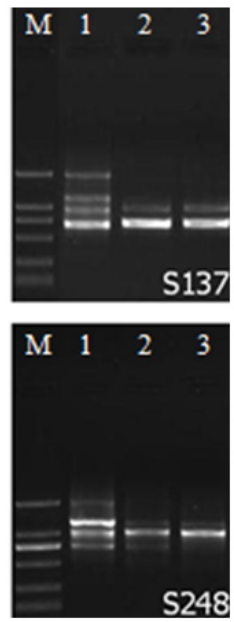

Fig. 1. Electropherogram of PCR amplication with eight different primers in primary screen M: Marker(DL 2000); 1: Ssud 1; 2: Sbic1; 3: Shal9 


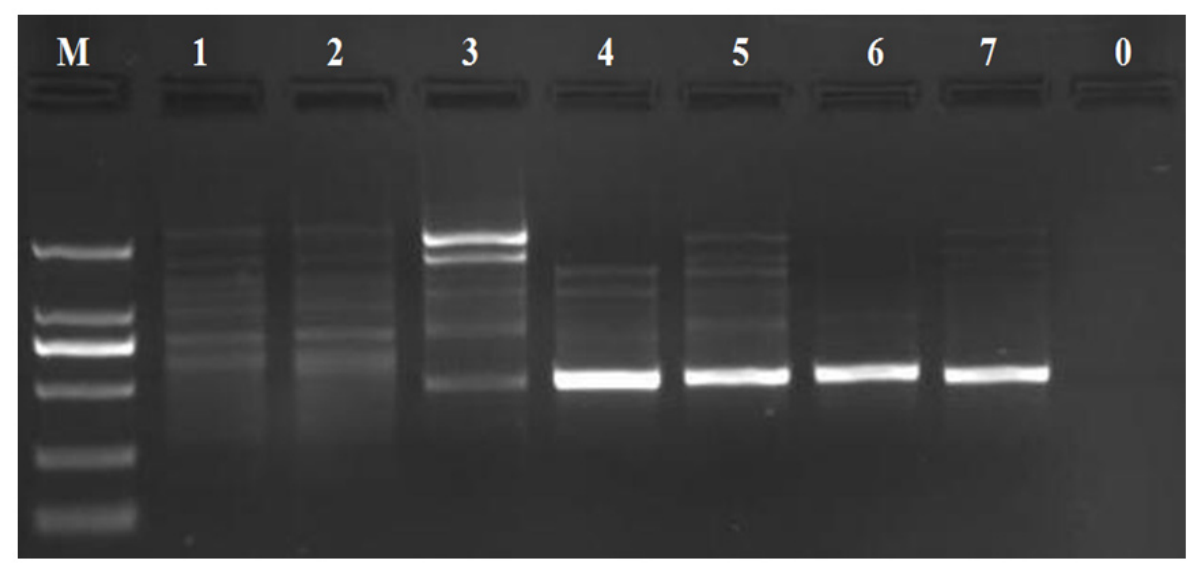

Fig. 2. PCR amplication electropherogram of RAPD primer $S 151$

M: Marker (DL 2000); 1: Ssud1; 2: Sbic1; 3: Salm3; 4: Shal1; 5: Shal2; 6: Shal12; 7 : Shal15

GAGTCTCAGGGTATGATCTGTTCGTCTTCCCTCAATTTTACGTCGCTCTGTCTCTGTTTG TTTCAGTAGCTCTGTCGTGCAGGTTCAATAGTTGTGTCATACCTGTTTTAGTAGGTCTGT TTAGTTGTTTCAGAAGATATCTGTTGTCTGTTCCTGTTATGTTTAAGTTCTGCGTATATGC CTCTGTTCTACAGTTCTGTTGTTTCGCTAGTATCTGTTTTTCTGTTATCTGTTTCGATAGT TGTATCATGTTTGGTGCTGTTGCAGATAATTATATACCATGCTATGCTTTGATATTTGATTT GCTTTATGGATCATGGTTACACGTCGTAATTATGATTCATGTCATATTTATATTTATCAATA ATATCATATATGTCATCATCATATTGTTAATTTATGGAATTAAAATGACATGGAAATTGCCT AATATCCTAACAGCAGCTGTCCACAAACCTGCATGCGTCTTGCCGCTAAGCGTGGATTT CGTCTGCTGCGCACCTGAGACTC

Fig. 3. Nucleotide sequences of the JGL0924 (The framed part is the sequences of RAPD primer S151)

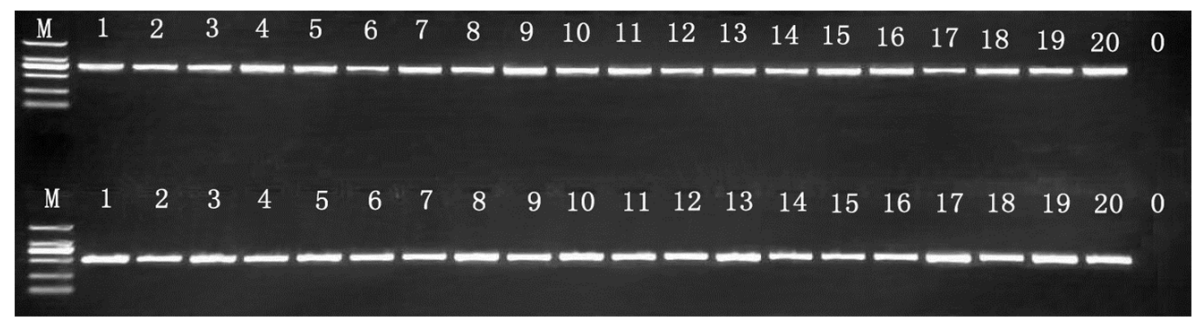

Fig. 4. Electropherogram of PCR amplication with CP3/CP4 and SH1/SH2 (1)

Upper line: universal primers (CP3/CP4), Lower line: primer SH1/SH2

M, DL2000 (TAKARA); 1 20, Shal1 Shal20; 0, negative control

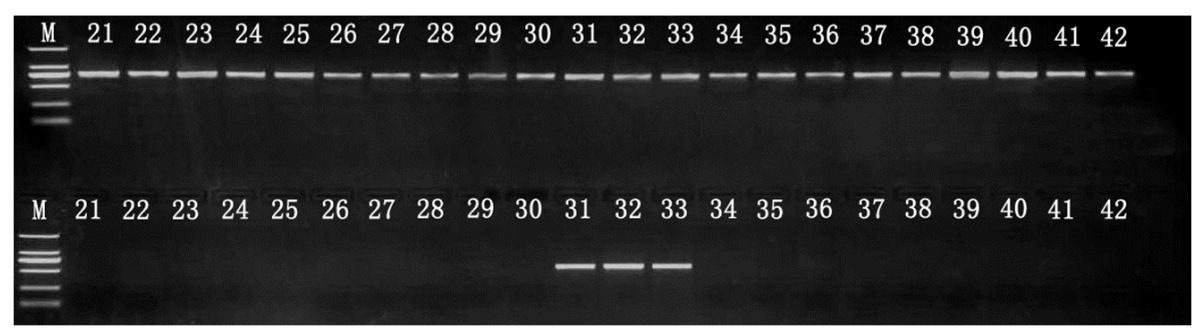

Fig. 5. Electropherogram of PCR amplication with CP3/CP4 and SH1/SH2 (2)

Upper line: universal primers (CP3/CP4), Lower line: primer SH1/SH2

M, DL2000 (TAKARA); 21 33, Salm1 Salm 13 and 34 42, Sbic1 Sbic9 
310

Tab. 2. Sequences of Primers for SCAR

\begin{tabular}{cc}
\hline Primer code & Sequence \\
\hline SH1 & 5'AGATTGAGTCTCAGGTGC-3' \\
SH2 & 5'-GAGTCTCAGGGTATGATCT-3' \\
\hline
\end{tabular}

negative. The results were repeatable and stable. The primers could be used to detect S.halepense except samples from Australia, improving the stability of molecular identification.

The results of the RAPD sorghum samples cluster analysis

Nineteen RAPD fingerprints of 17 sorghum genus samples obtained, two pieces of fingerprints were shown in Fig. 7 as examples. All the bands on the fingerprints were cluster analyzed. The dendrogram of 17 sorghum samples based on variation in RAPD fingerprints were shown in Fig. 8. The dendrogram was divided into two main groups. One group included $S$. halepense and $S$. almum, and the other group was $S$. bicolor. In the first group, four $S$. halepense samples and three $S$. almum samples were clustered together as same sub-group, and the rest of $S$. almum samples were clustered as another sub-group. It could be found in the $S$. almum sub-group the genetic distance of the $5 \mathrm{~S}$. almum samples from Australia and Ethiopia was very short, so the $5 \mathrm{~S}$. almum samples were gathered together. Other four $S$. almum samples from Argentina were gathered together. The analysis results showed that the genetic material of $S$. almum was significantly different with the geographical distribution. Another three $S$. almum samples and four $S$. halepense samples were gathered together, indicating insignificant difference between S. almum and $S$. halepense.

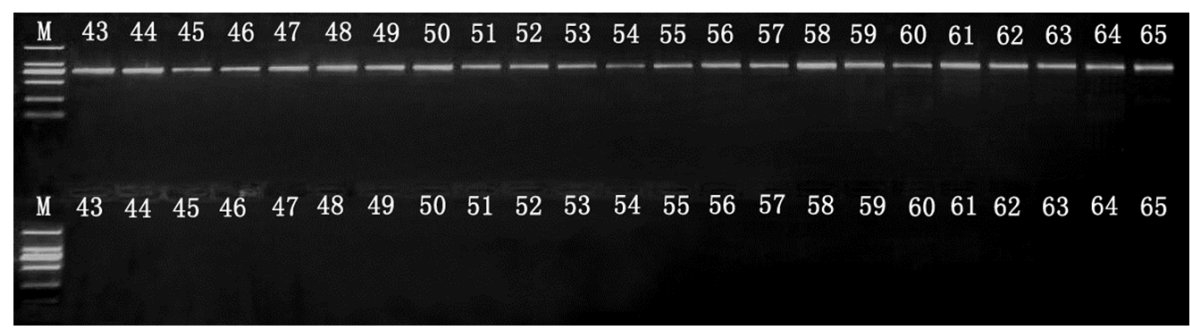

Fig. 6. Electropherogram of PCR amplication with CP3/CP4 and SH1/SH2 (3)

Upper line: universal primers (CP3/CP4), Lower line: primer SH1/SH2

M, DL2000 (TAKARA); 43, Shyb1; 44, Svul1; 45 48, Ssac1 Ssac4; 49 52, Snit1 Snit4; 53, Saru1; 54, Sver1; 55 58, Sdru1 Sdru4; 59 62, Ssud1 Ssud4; 63, Silk1; 64 65, Spro1 Spro2

Tab. 3. Verification results of the SCAR primers $\mathrm{SH} 1 / \mathrm{SH} 2$ for $S$. halepense

\begin{tabular}{|c|c|c|c|c|c|c|c|}
\hline Code & Result & Code & Result & Code & Result & Code & Result \\
\hline Shall & + & Shal18 & + & Sbic2 & - & Snit4 & - \\
\hline Shal2 & + & Shal19 & + & Sbic3 & - & Sarul & - \\
\hline Shal3 & + & Shal20 & + & Sbic4 & - & Sver1 & - \\
\hline Shal4 & + & Salm1 & - & Sbic 5 & - & Sdrul & - \\
\hline Shal5 & + & Salm2 & - & Sbic6 & - & Sdru2 & - \\
\hline Shal6 & + & Salm3 & - & Sbic7 & - & Sdru3 & - \\
\hline Shal7 & + & Salm4 & - & Sbic8 & - & Sdru4 & - \\
\hline Shal8 & + & Salm5 & - & Sbic9 & - & Ssud1 & - \\
\hline Shal9 & + & Salm6 & - & Shybl & - & Ssud2 & - \\
\hline Shal10 & + & Salm7 & - & Svull & - & Ssud3 & - \\
\hline Shall1 & + & Salm8 & - & Ssacl & - & Ssud4 & - \\
\hline Shal12 & + & Salm9 & - & Ssac2 & - & Silk1 & - \\
\hline Shal13 & + & Salm10 & - & Ssac3 & - & Sprol & - \\
\hline Shal14 & + & Salm11 & + & Ssac4 & - & Spro2 & - \\
\hline Shal15 & + & Salm12 & + & Snitl & - & & \\
\hline Shall6 & + & Salm13 & + & Snit2 & - & & \\
\hline Shall7 & + & Sbicl & - & Snit3 & - & & \\
\hline
\end{tabular}



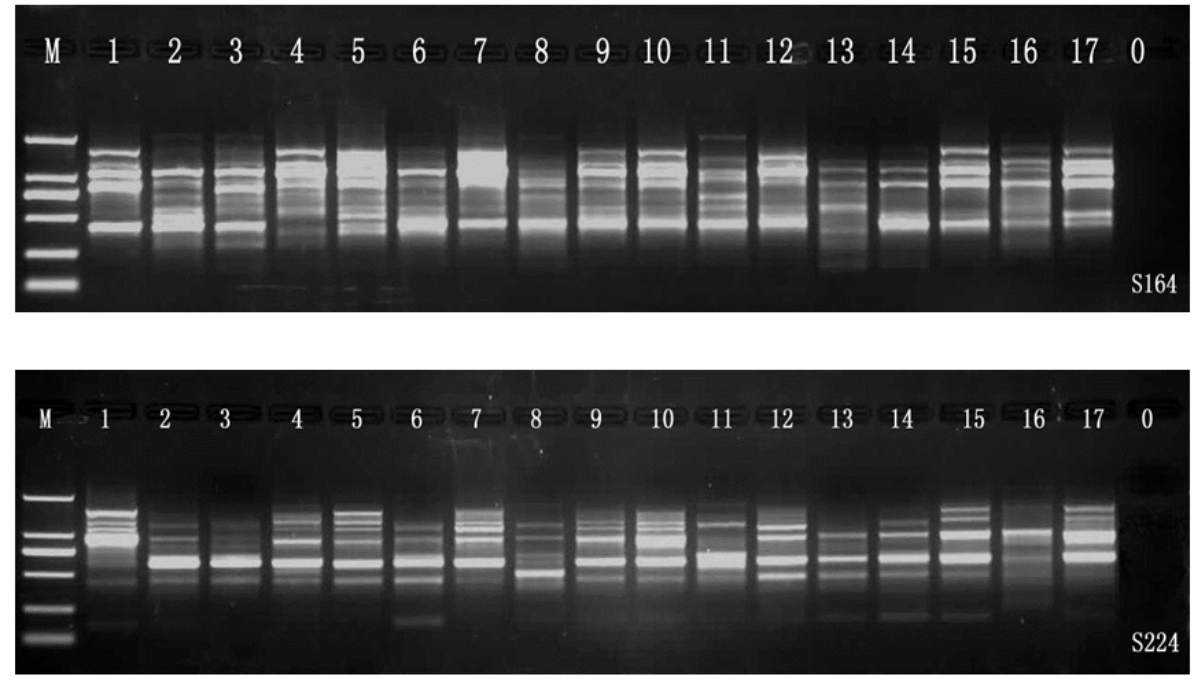

Fig. 7. Electropherogram of RAPD-PCR amplication with two RAPD primer (S164, S224)

Left: primer S164, Right: primer S224

M, DL2000 (TAKARA); 1, Sbic9; 2, Shal12; 3, Shal15; 4, Shal7; 5, Shal19; 6, Salm 10; 7 , Salm8; 8, Salm3; 9, Salm4; 10, Salm9; 11; Salm5; 12, Salm2; 13, Salm11; 14, Salm 12; 15, Salm6; 16, Salm8; 17, Salm7

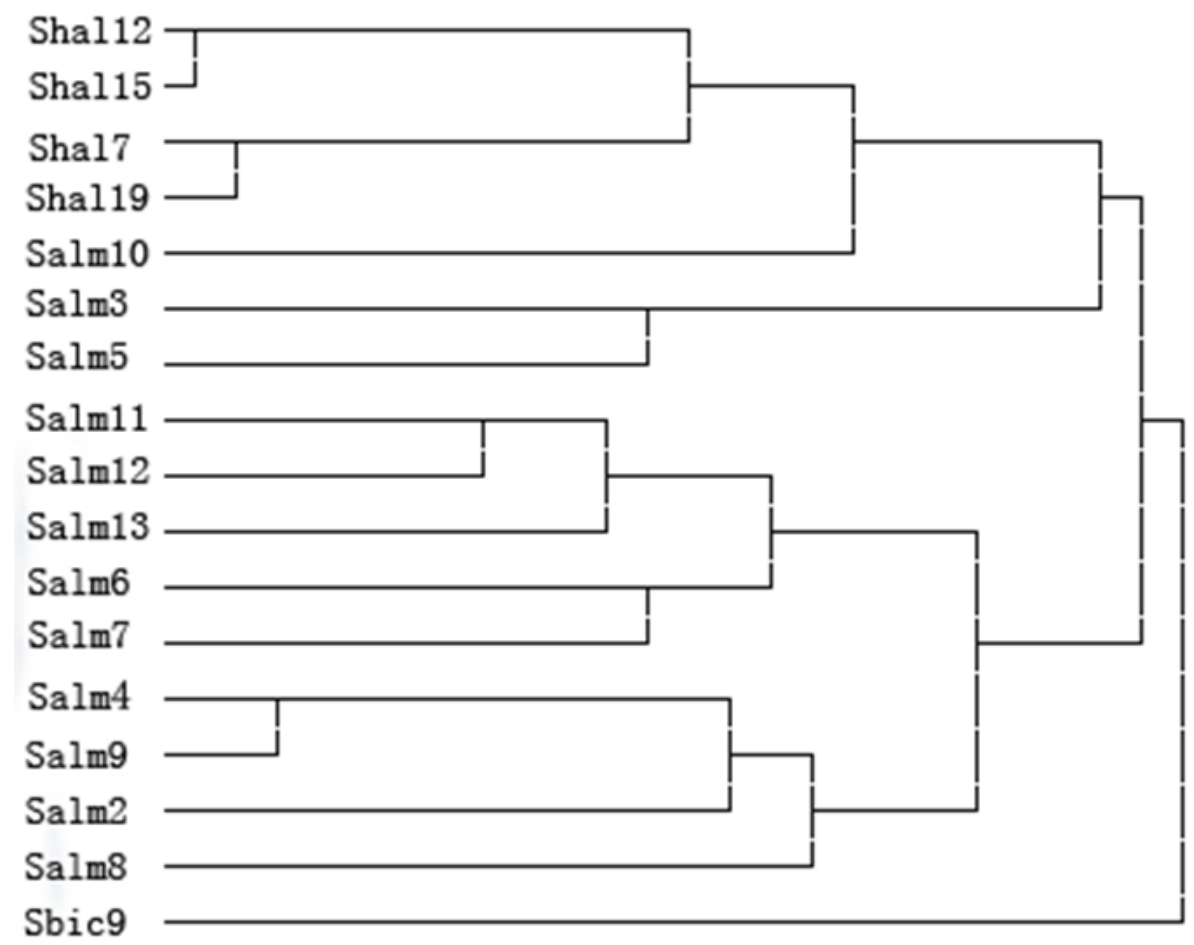

Fig. 8. Dendrogram of 17 sorghum samples based on variation in RAPD Fingerprinting

\section{Discussion}

The results showed that the RAPD marker could be successfully converted into a specific SCAR marker for rapid identification of $S$. halepense except Australia genotype of S. almum, improving the stability of molecular identification. For the hybridization is common in plantae, there is no strict reproductive isolation between different species hence many intermediate species exist. The SPSS cluster analysis results of the RAPD fingerprints showed that the close genetic relationship of $S$. almum and $S$. halepense, and $S$. almum was hybridization from $S$. halepense with $S$. bicolor, S. sudanse or S. arundinaceum (Zhang et al., 1993). Therefore, we speculated that the three $S$. almum samples from Australia may be the medium species of $S$. halepense and $S$. almum, and this geotype of $S$. almum just inherited the specific site of $S$. halepense we found in the RAPD marker, leading to a positive result.

From the results we found that the specific band of $S$. balepense amplified by the SCAR primers was distinct. 
312

Comparing with RAPD marker, the sensitivity of the reaction conditions of the SCAR marker was lower. This method reduced the environmental impact on the experimental results, owning higher specificity and repeatability. It reduces the instability of RAPD markers, avoids the complication and high financial cost of AFLP markers. SCAR marker is an ideal tool for molecular identification of species (Yan et al., 2003). Though there are many reports on conversion of RAPD markers into SCAR markers successfully (Paran and Michelmore, 1993), the success rate of SCAR marker conversion is very low, which act as a main obstacle during the conversion process and developing of SCAR markers. The low success rate also results in difficulty in conversion to ensure the specificity of the primers after lengthening the RAPD primers. The next step of our study should include: (1) To further optimize the reaction conditions for specific amplification, increase the annealing temperature to ensure the specificity of the SCAR primers, and shorten the specific amplification primers length to increase the success rate of SCAR marker conversion; (2) To ensure the specificity of SCAR primers, amplify and sequence two adjacent sides of the sequence by reverse PCR, extend the 5 'end of RAPD primers to a certain length, resynthesis primers near the 5 ' end to avoid covering polymorphism sites; (3) To further verify and analyze through Southern blot or design other primers. Since SCAR markers have stronger reproducibility over RAPD markers, convert the dominant RAPD markers into codominant markers, and owns the STS markers advantages, it improves the rate of gene mapping and molecular mapping. SCAR markers have a potential application in germplasm identification on $S$. halepense etc., more specific SCAR markers for S.halepense should be found in future work.

\section{Conclusions}

In this study, sequence characterized amplified regions (SCAR) marker of Johnsongrass was successfully established via conversion of the RAPD marker. This SCAR marker is much more stable, effective and accurate than RAPD markers, which was successfully applied to distinguish Johnsongrass and its relatives. We believe that this technique of conversion from RAPD marker to SCAR marker could also be widely used in fields of bio-detection, including malignant weed discriminating, species relationship analyzing, genetic disease-associated genes screening, genetically modified food detection and so forth.

\section{Acknowledgments}

The authors wish to thank Dr Sally Norton (Australian Tropical Grains Germplasm Centre) for the Australian specimens provided and thank Zhang Xiabing (University of Southern California) for polishing the language of this paper. This study was supported by project of PRC State Administration for Quality Supervision Inspection and Quarantine (AQSIQ)(No. 200810787), Ministry of National Science and Technol- ogy Projects(No.2012BAK11B03), Shanghai Science and Technology Committee (No. 08DZ2270800), Shanghai University (No. SHUCX102290), and the Major Basic Research Program of Shanghai Municipal Science and Technology Commission (No.08JC1409600).

\section{References}

Chen L, Yu FL, Yang YJ, Chen DM, Xu CJ, Gao QK (1999). A study on genetic stability of excellent tea germplasms [ $\mathrm{Ca}$ mellia sinensis (L.) O.Kuntze] using RAPD markers. J Tea Sci 19:13-16.

Chen Q, Wei SS, Deng ZR, Yin LP, He B, Kong XL (2009). Optimization of DNA extraction from seeds of Sorghum sudanense (Piper) Stapf. Not Bot Horti Agrobo 37:256-260.

Fang XE, Chen Q, Yin LP, Wang W (2008). Application of ISSR in genetic relationship analysis of sorghum species. Acta Agron Sinica 34:1480-1483.

Guo QX, Huang KH, Yu Y (2005). Differentiation of Sorghum halepense and $S$. silk by PCR-RFLP method. Plant Quarantine 19:330-333.

Holm LG, Plucknett DL, Pancho JV, Herberger JP (1977). The world's worst weeds-distribution and biology. Univ Press of Hawaii, Honolulu.

Li JQ, Wang LH, Zhan QW, Li YF (2007). A study on genetic variation of two species of sorghum by RAPD markers. Acta Prataculturae Sinica 16:140-144.

Jang CS, Kamps TL, Tang H, Bowers JE, Lemke C, Paterson $\mathrm{AH}$ (2009). Evolutionary fate of rhizome-specific genes in a non-rhizomatous Sorghum genotype. Heredity 102:266273.

Kesseli RV, Paran I, Michelmore RW (1992). Efficient mapping of specifically targeted genomic regions and the tagging of these regions with reliable PCR-based genetic markers, 3136 p. In: American Society of Agronomy (Ed.). Symposium Applications of RAPD Technology to Plant Breeding. ASA, Minneapolis and Madison.

Paran I, Michelmore RW (1993). Development of reliable PCRbased markers linked to downy mildew resistance genes in lettuce. Theor Appl Genet 85:985-993.

Penner GA, Bush A, Wise R, Kim W, Domier L, Kasha K, Laroche A, Scoles G, Molnar SJ, Fedak G (1993). Reproducibility of random amplified polymorphic DNA (RAPD) analysis among laboratories. PCR Methods Appl 2:341-345.

Williams JGK, Kubelik AR, Livak KJ, Rafalski JA, Tingey SV (1990). DNA polymorphisms amplified by arbitrary primers are useful as genetic markers. Nucl Acids Res 18:6531-6535.

Yan NH, Chen J, Ma XR, Deng GB, Yu MQ (2003). Conversion of RAPD marker to SCAR marker of wheat cereal rootknot nematode-resistant gene rkn-mnl. Chin J Appl Environ Biol 9:250-253

Yin LP, Deng C, Yi JP, Wu H (2004). A study of the homology of Sorghum halepense and its relative species. Plant Quarantine 18:232-236.

Zhang JL, Yin LP, Zhang ZX (1993). The weed-Sorghum almum. Plant Quarantine 7:122-123. 